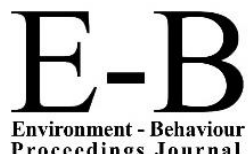

Environment - Behaviour
Procecedings Journal
AIVCE-BS-1, 2020ShahAlam

https://www.amerabra.org; https://fspu.uitm.edu.my/cebs; https://www.emasemasresources.com/ AMEABRA International Virtual Conference on Environment-Bahaviour Studies, $1^{\text {st }}$ Series cE-Bs, FSPU, Universiti Teknologi MARA, Shah Alam, 24-25 Jun 2020

\title{
The Accommodation Response and Facility between Children and Young Adults
}

\author{
Aresya Najmee, Saiful Azlan Rosli, Syazwina Batrisya Jalaludin \\ ${ }^{1}$ Department of Optometry, Faculty of Health Sciences, \\ Universiti Teknologi MARA Cawangan Selangor 42300 Bandar Puncak Alam, Selangor Malaysia \\ aresyanajmee@uitm.edu.my, saifulazlan010@gmail.com, syazwinabatrisyiakhan@gmail.com \\ Tel: 0179450024
}

\begin{abstract}
Tonic accommodation decreased with age among children. In young adults, late-onset myopia will develop due to occupational near vision demands. This study aims to investigate the accommodation response and facility between children and young adults, in emmetrope (non-myopic) and myope group. The accommodation response and facility of young adults and children were measured using monocular estimation method (MEM), monocular accommodative facility (MAF) and binocular accommodative facility (BAF) with an exposure of near task for 15 minutes. Near task has significantly increased the lag of accommodation in all groups $(p<0.05)$. However, the accommodation facility was not affected by near work in all groups $(p>0.05)$.
\end{abstract}

Keywords: accommodation response, accommodation facility, myopes, emmetropes

eISSN: 2398-4287@ 2020. The Authors. Published for AMER ABRA CE-Bs by e-International Publishing House, Ltd., UK. This is an open access article under the CC BYNC-ND license (http://creativecommons.org/licenses/by-nc-nd/4.0). Peer-review under responsibility of AMER (Association of Malaysian Environment-Behaviour Researchers), ABRA (Association of Behavioural Researchers on Asians) and cE-Bs (Centre for Environment-Behaviour Studies), Faculty of Architecture, Planning \& Surveying, Universiti Teknologi MARA, Malaysia.

DOI: https://doi.org/10.21834/ebpj.v5i14.2168

\subsection{Introduction}

Accommodation is defined as the ability of the eye to change its focus from distant to near objects, and vice versa. This process is achieved by the lens changing its shape. Accommodation is the adjustment of the optics of the eye to keep an object in focus on the retina as its distance from the eye varies. It is the process of adjusting the focal length of a lens. Numerous studies discussed the relation of near work, accommodation response, and myopia. However, up to this date, it is still at the phase of undeniable argument. There was no difference in ocular rigidity between emmetropic and myopic children (Laughton et al., 2017; Mallen et al., 2006). Ocular rigidity is a worthy subject for further investigation, particularly in young adult emmetropes who may be at risk of the development of late-onset myopia due to occupational near vision demands (near work). Working on near work, which increases the near work demand, is an adapted lifestyle nowadays to the multitasking task required anywhere, especially for the leisure and working activities. This involves transforming the human mobility pattern that influences micro-level human behavior and well-being (Wu et al., 2016)/

Myopia has been recognized as a significant public health concern due to the prevalence of myopia. It has rapidly increased in the past 50-60 years, especially in developed countries, such as Singapore, China, Taiwan, Hong Kong, Japan, and Korea (Morgan et al., 2012). The risk factors for myopia included more time spent on the near-work activity, less time spent in outdoor activities, higher educational level, parental history of myopia, and a relatively hyperopic periphery (Hsu et al., 2016). A comparison between myopic and emmetropic groups among children and two refractive groups in adults found that myopes in both ages did show low tonic accommodation compared to emmetropes (Zadnik et al., 1999). However, the results of the study showed that tonic accommodation decreases with age. In contrary, the study by Gwiazda \& Bauer has found no association between near work and age as they stated the smallest initial values of tonic accommodation and the largest inward shifts after near work occur during the period of acquisition

eISSN: 2398-4287@ 2020. The Authors. Published for AMER ABRA cE-Bsby e-International Publishing House, Ltd., UK. This is an open access article under the CC BYNC-ND license (http://creativecommons.org/licenses/by-nc-nd/4.0/). Peer-review under responsibility of AMER (Association of Malaysian Environment-Behaviour Researchers), ABRA (Association of Behavioural Researchers on Asians) and cE-Bs (Centre for Environment-Behaviour Studies), Faculty of Architecture, Planning \& Surveying, UniversitiTeknologi MARA, Malaysia.

DOI: https://doi.org/10.21834/ebpj.v5i14.2168 
and progression of myopia, whether found in children or adults were insignificant (Gwiazda et al., 1995). To support the previous study, Gwiazda and associates have confirmed that there was no association between different age groups. However, the correlation between different refractive errors exist, as increasing myopia, the accommodation will be decreasing (Gwiazda et al., 1995).

\subsection{Literature Review}

Several studies have shown a significant correlation between refraction and the amount of accommodation and near work. The study conducted on microscopists has shown most of the microscopists developed myopia after beginning the job, indicating, that near-work triggers the mechanism for the development of myopia (Drexler et al., 1998). Epidemiologic studies have shown correlations between myopia and near visual tasks that require accommodation (Gwiazda et al., 1993). A reduced ability to accommodate for near targets has been a causative factor in the development of myopia. It is known that adults who were myopic since children accommodate significantly more than emmetropic subjects when viewing close targets. Prolonged near work appears to be associated with myopic development, and accommodation might not link between near work and myopia (Chen, Schmid, \& Brown, 2003). However, one fact is that if accommodative accuracy during near work is not maintained, defocused retinal image results will then lead to myopic development. In considering whether variations in accommodation will lead to the development of myopia, there is evidence demonstrating differences in accommodative responses between myopic and non-myopic individuals. Several investigators have stated that myopic individuals may demonstrate differences in their accommodation responses compared with the emmetropic. This study claimed an imbalance of the autonomic nervous system might give rise to anomalous accommodation responses during or following sustained near work (Chen, Schmid, Brown, et al., 2003). The delay in the relaxation of accommodation back to a baseline after a sustained near-vis task was termed near-work-induced transient myopia (NITM).

Myopes have a greater NITM than emmetropes and hypermetropic. It has been proposed that frequent, intense near work tasks and the defocus caused by accommodative hysteresis over a prolonged period may trigger the development of myopia (Wolffsohn et al., 2003). Many studies have stated that near work is a primary and environmentally based factor in myopia's development and progression. Furthermore, there is also sufficient supportive evidence from various studies such as clinical, laboratory, modelling and epidemiological in humans using a meta-analysis approach and add up that in the absence of visual stimulation the lens of the young intermediate in humans eye assumes a resting position, dioptric power between far and near points, called tonic accommodation (TA) (Ciuffreda \& Vasudevan, 2008; Gwiazda et al., 1995).

The relationship between TA and error in adults has been widely investigated, and the most significant finding is that myopes have lower TA values compared to emmetropes. The effects of cognitive demand on accommodation vary between different refractive groups, with myopes having a lower tonic accommodation than emmetropes before exposure to the task. However, following a task, they showed a positive shift in tonic accommodation that was significantly higher than the shift for emmetropes (Wolffsohn et al., 2003). Now, to explain the relationship between tonic accommodation and accommodation response, Liu et al. have found a significant correlation between tonic accommodation and closed-loop accommodation response (Liu et al., 2016). Closed-loop accommodation response defines the accommodation response being measured under natural viewing conditions, and most of the studies conducted to measure the accommodation response under closed-loop accommodation. Thus, this study was a cross-sectional study to measure the accommodation response and facility under closed-loop view to observe the accommodation response and facility before and after the near task (reading task) between groups of children, adults, emmetrope and myope.

\subsection{Methodology}

The Research Ethics Committee approved this study of MARA University of Technology. All subjects involved in this study participated voluntarily. A total of 40 subjects were participated in this study and has been divided into two groups of age, which were school-aged children (13.95 \pm 2.40 years old) and young adults $(22.9 \pm 1.41$ years old). The young adults were taken from Optometry students of UiTM Puncak Alam, whereas the children were taken from two Maahad Tahfiz school in Puncak Alam. The participant's refractive errors were also taken into account. Half of the young adults were emmetropes of spherical equivalent power $+0.50 \mathrm{DS}$ to $-0.50 \mathrm{DS}(+0.50 \pm$ $0.37 \mathrm{D})$, and half were myopes of spherical equivalent power $-0.75 \mathrm{DS}$ or below $(-1.85 \pm 1.15 \mathrm{D})$. The school-aged children were the active learners at school with mostly emmetropes, $(+0.25 \pm 0.15 \mathrm{D})$ and only 5 of them were myopes with a range of power $(-1.60 \pm$ 0.79D)

Young adults consist of 4 boys (20\%) and 16 girls (80\%). For the school-aged children, 7 were girls (35\%), and the rest were boys $(65 \%)$. All of the subjects were refracted with non-cycloplegic distance retinoscopy and assessed with some binocular vision assessments before each test session. Subjects who have these criteria were excluded from the experiment; (i) refractive errors with spherical equivalent power more than $+0.50 \mathrm{DS}$ to $-0.50 \mathrm{DS}$ (ii) have binocular vision problems such as accommodation and vergence anomalies, (iii) cover test showed any eye deviation, (iv) stereopsis of 60 second of arc or worse, (v) ocular motility showed any muscle restriction, (vi) pupil response showed abnormalities such as relative afferent pupillary defect (RAPD), (vii) have significant health or ocular history and (viii) not achieve 6/6 after being corrected. Eye screening was done at the primary optometry clinic in UiTM Puncak Alam for university students, and for school children, the screening was performed at the school, as in Figure 1. Informed consent was obtained from the parents and assent from the subjects after the study was explained. 


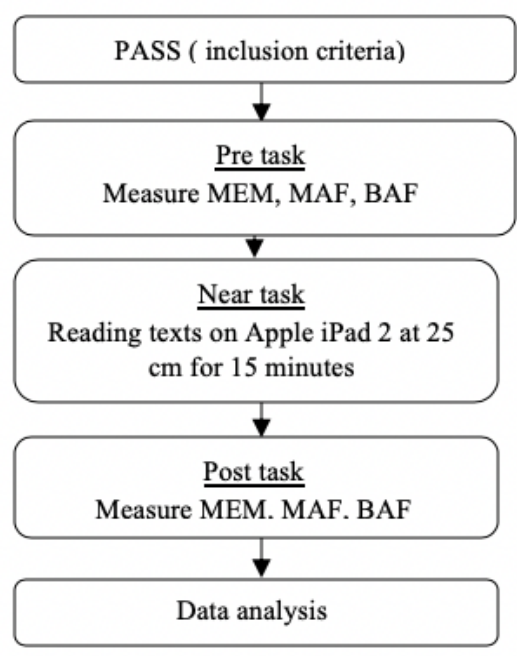

Figure 1: Flowchart of the study

\subsection{Materials}

Two Bahasa Melayu text of Kisah 25 Nabi dan Rasul (Fapet, ND) for the young adults and Khutbah Jumaat (JAIS, 2019) for the schoolaged children with black printed text on a white background, letters of Arial size N12 $(2 \times 3 \mathrm{~cm})$ that were displayed on Apple iPad 2 of size 9.7-inch (1024x768, 132 PPI) multitouch "glossy" LED-backlit IPS display, and width and height of 9.5 inches by 7.31 inches, with the depth of 0.34 inch thick. The iPad was positioned $25 \mathrm{~cm}$ from the subject's eye as a near accommodative stimulus in a bright room of 273 lux. The reading material and room setting were kept constant for both children and young adults.

\section{Monocular estimation method (MEM)}

Monocular estimation method (MEM) dynamic retinoscopy is a widely used objective clinical test for the accommodative response that resulted in lag or lead of accommodation. In a recent American Optometric Association Clinical Practice Guideline, it is specifically recommended as a useful clinical test. MEM is valid and reliable. The investigators concluded that the range of normal values for MEM is 0.00 to $\leqslant 0.75 \mathrm{D}$, while less than that showed lead accommodation and more than that showed lag of accommodation (Tassinari, 2002). MEM was done in a half-dim room with the subject wearing their habitual correction on or their final subjective power on, to eliminate other factors of accommodation anomalies. MEM was performed using a Welch-Allyn spot retinoscope. MEM target was the Pierce MEM cards clipped to the retinoscope. In this study, we used the Grade 6 card which displayed 12 different words on the card for the adults, and they need to read aloud those words. For children, we used the figure's card and ask them to say aloud what they could see on the cards. The influence of this difference in target size was not included in the data collection or analysis because the influence of letter-size or figures on accommodative response is thought to be negligible (Tassinari, 2002). MEM was done at the distance of $50 \mathrm{~cm}$ from the subjects' eyes. The retinoscopy beam was swept onto each eye, to see the nature of reflex. The retinoscopy reflex was then first estimated, and then a measuring lens was used to confirm the estimation. If a 'with' motion was seen, the plus lens was used to neutralize by using intervals of $+0.25 \mathrm{DS}$ and if the reflex showed an 'against' motion, a minus lens was used to neutralize the reflex. The MEM value was taken when the neutralized reflex was seen.

\section{Monocular accommodative facility (MAF) and Binocular accommodative facility (BAF)}

Monocular accommodative facility (MAF) or Binocular accommodative facility (BAF) was used to evaluate the ability of the eye to alter accommodation rapidly and accurately, and this test was considered a part of an ocular examination. The patient has given a hand-held flipper containing a pair of $\leqslant-2.00 \mathrm{D}$ lenses on one side and $\geqslant+2.00 \mathrm{D}$ lenses on the other side and is instructed to clear a word of near Snellen chart on line $\mathrm{N} 6$ at $0.4 \mathrm{~m}$ through one pair of lenses and to flip to the other pair as soon as the print is readable. A pair of positive and negative flips is considered as one cycle, and the number of cycles completed in a minute is recorded as the result of the value of their accommodative facility (Radhakrishnan et al., 2007). MAF was recorded monocularly with the other eye occluded while BAF was recorded binocularly. In this study, there was an insignificant difference of MAF value on the right and left eye, hence only one eye was used to measure the MAF value.

All subjects were compulsory for the screening part. Then, the subjects who passed the screening test were taken into iROViS Puncak Alam, to further the data collection. Subjects were seated and given a brief explanation of the procedure of the study. Then, a consent form is given for them to sign. With their habitual correction on or final subjective refraction that was put on a trial frame, the subject was then performed with monocular estimation method (MEM) dynamic retinoscopy to measure the before task accommodative response which requires them to look on the card clipped on the retinoscope in a half-dim room and say aloud the words or figures seen. Next, monocular accommodative facility (MAF) was done on each eye with the other eye occluded, for 1 minute each, then binocular accommodative facility (BAF) was measured, both in a full bright illumination room. MAF and BAF were done to measure the before task accommodative facility. 
Later on, subjects were introduced to the near task which was reading texts on Apple iPad 2 at the distance of $25 \mathrm{~cm}$, where the subjects need to read it for 15 minutes. A timer was set for 15 minutes, and the subjects were monitored during that time interval to ensure that the eyes were always focused on reading the texts and also to ensure the reading distance was kept constant by using a measuring tape. When 15 minutes were up, the measurement of the MEM retinoscopy, MAF and BAF were repeated in the same order as initially for the after task accommodative response and facility result. During the transfer, from the end of the task to post-task measurement, it took less than three minutes to measure all measurements to avoid transient adaptation effects. The accommodation would change after 3 minutes exposed to a different stimulus (Gwiazda et al., 1995). Finally, the subjects were dismissed.

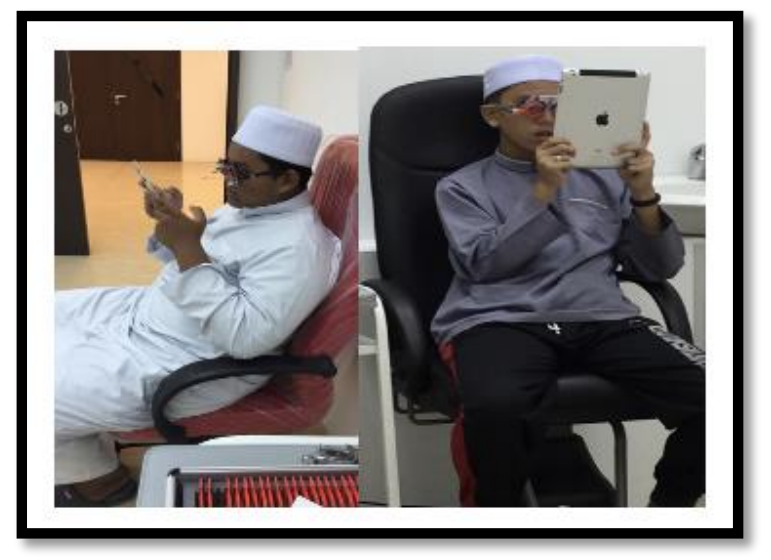

Figure 2: Two children subjects performing near task for 15 minutes

Normality test was done using the Shapiro-Wilk test as the sample size was less than 50 . Then, paired t-test was performed to establish whether a statistically significant difference $(p<0.05)$ existed between two different variables which were first, children and young adults before and after near task and secondly, myope and emmetrope before and after the near task. At least $15^{\circ}$ of freedom is recommended due to repeated measure designs. Significance of the result was recorded with $p$-value being less than 0.05 while the result of $p$-value more than 0.05 were considered insignificant.

\subsection{Findings}

Figures 3 to 6 showed the significant results of accommodation response measured using monocular estimation method (MEM) dynamic retinoscopy before and after the task $(p<0.05)$ for children and adult, emmetrope and myope group. Children have higher lag of accommodation after exposed to near task $(1.06 \pm 0.29 \mathrm{D})$ compared to before exposed to near task $(0.79 \pm 0.25 \mathrm{D})$, with a statistically significant increase of $0.28(95 \% \mathrm{Cl}, 0.17$ to 0.38$) \mathrm{D}, \mathrm{t}(19)=5.40, \mathrm{p}<0.01$ as shown in (Figure 3$)$. Young adults shows higher lag of accommodation after exposed to near task $(1.06 \pm 0.32 \mathrm{D})$ compared to before exposed to near task $(0.81 \pm 0.32 \mathrm{D})$,a statistically significant increase of $0.25(95 \% \mathrm{Cl}, 0.16$ to 0.34$) \mathrm{D}, \mathrm{t}(19)=5.63, \mathrm{p}<0.01$ (Figure 4).

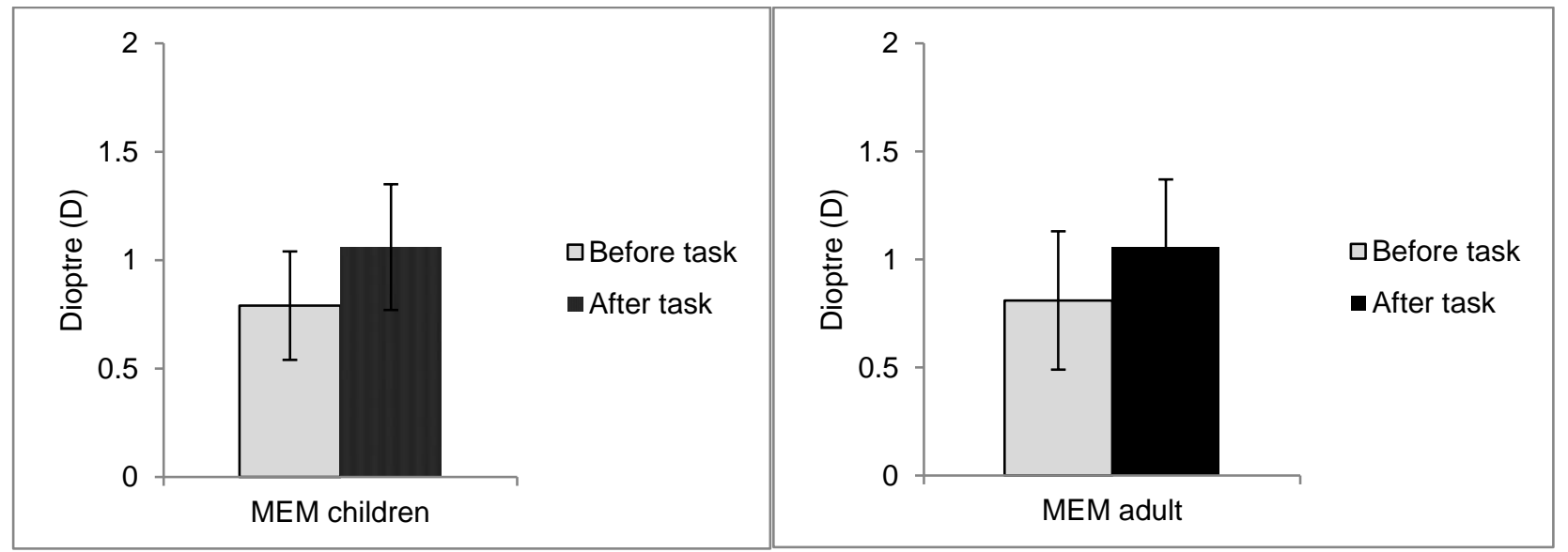

Figure 3 and 4: The significant effect of near task on MEM for children and adult $(p<0.05)$

Meanwhile, emmetropes gives higher lag of accommodation after exposed to near task $(1.12 \pm 0.25 \mathrm{D})$ compared to before exposed to near task $(0.8167 \pm 0.27 \mathrm{D})$, a statistically significant increase of $0.30(95 \% \mathrm{Cl}, 0.18$ to 0.42$) \mathrm{D}, \mathrm{t}(14)=5.39$, $p<0.01$ as shown in (Figure 5). Myopes also shown a higher lag of accommodation after exposed to near task (1.05 $\pm 0.38 \mathrm{D})$ compared to before exposed to near task $(0.72 \pm 0.33 \mathrm{D})$, with a statistically significant increase of $0.33(95 \% \mathrm{Cl}, 0.22$ to 0.45$) \mathrm{D}, \mathrm{t}(14)=6.33$, p<0.01 (Figure 6).Besides, even a significant effect of accommodation response following the near task on both refractive groups, but neither showed higher 
accommodation lag than the other when compared between the two groups. In contrary, figures 7 to 14 showed the insignificant result of accommodation facility for both neither monocular nor binocular (MAF) and (BAF) before and after the task ( $>>0.05$ ) on all groups tested.

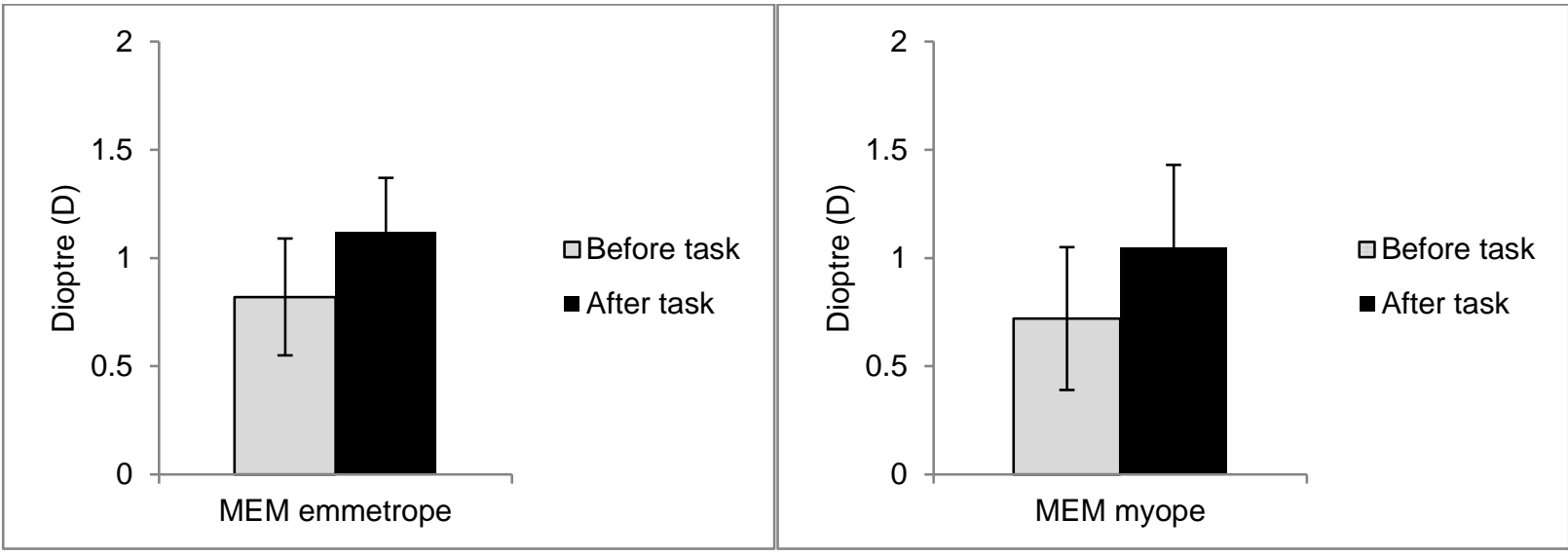

Figure 5 and 6: The significant effect of near task MEM for emmetropes and myopes for children and adults $(p<0.05)$

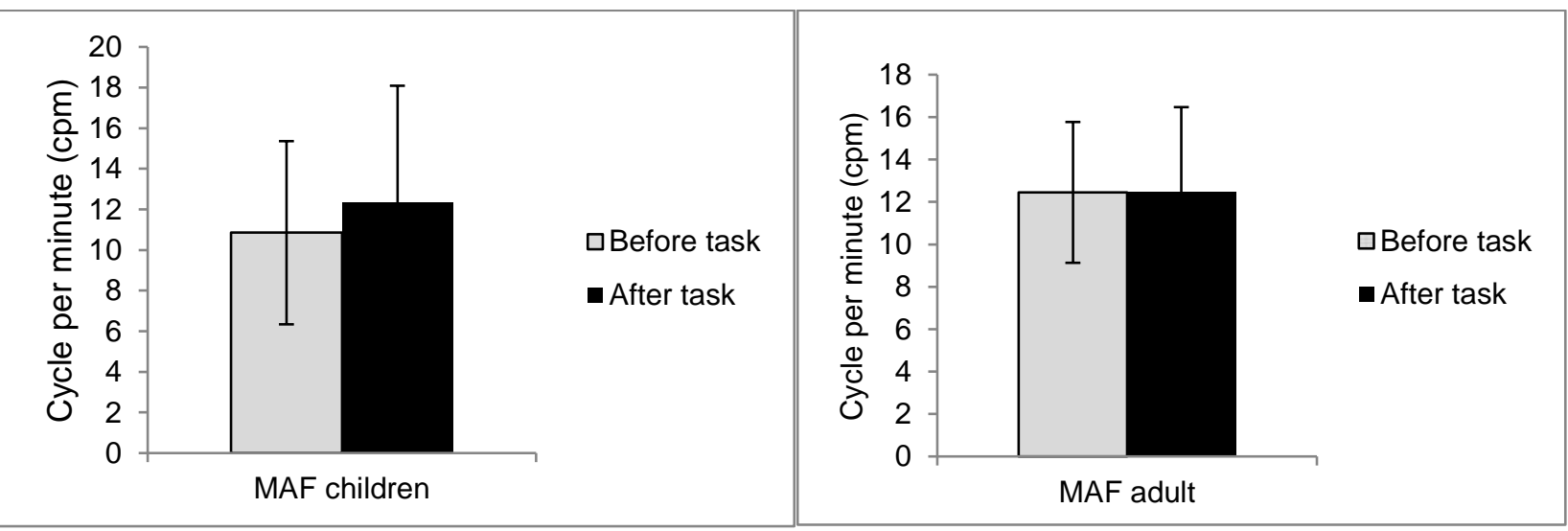

Figure 7 and 8: The insignificant effect of near task on MAF for children and adults $(p>0.05)$

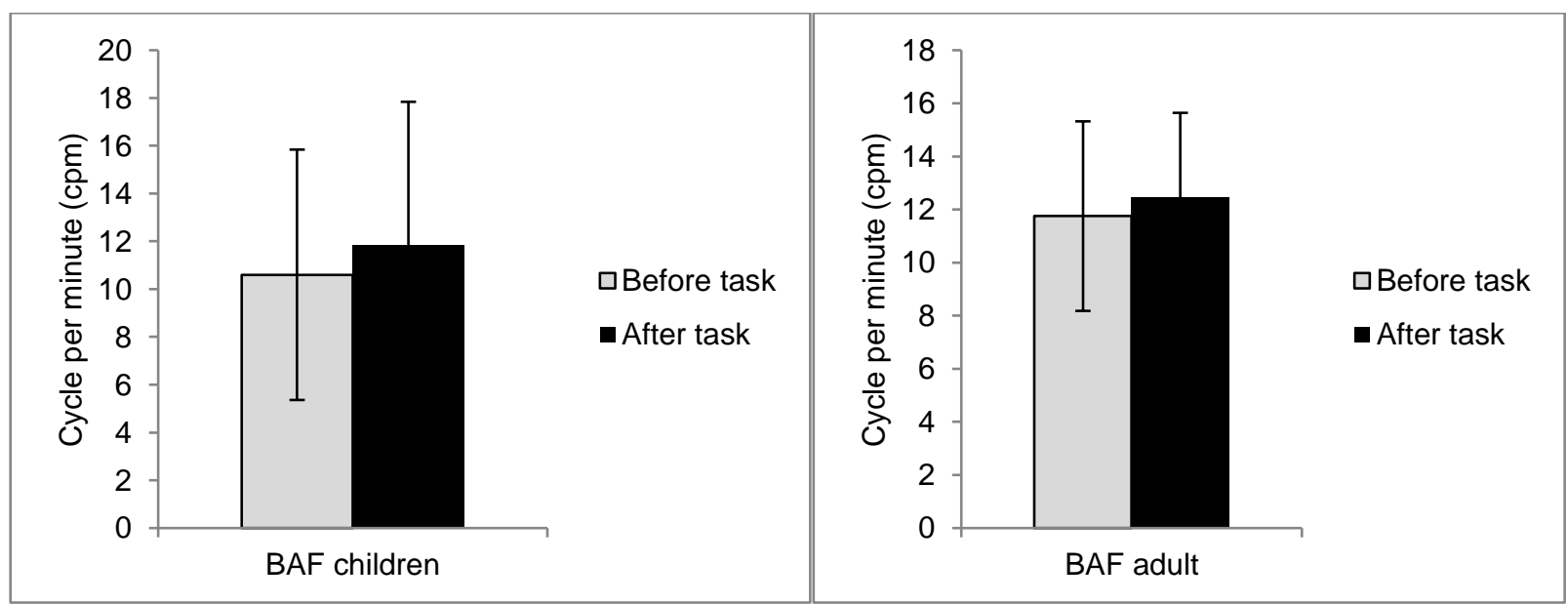

Figure 9 and 10: The insignificant effect of near task on BAF for children and adult( $(p>0.05)$ 


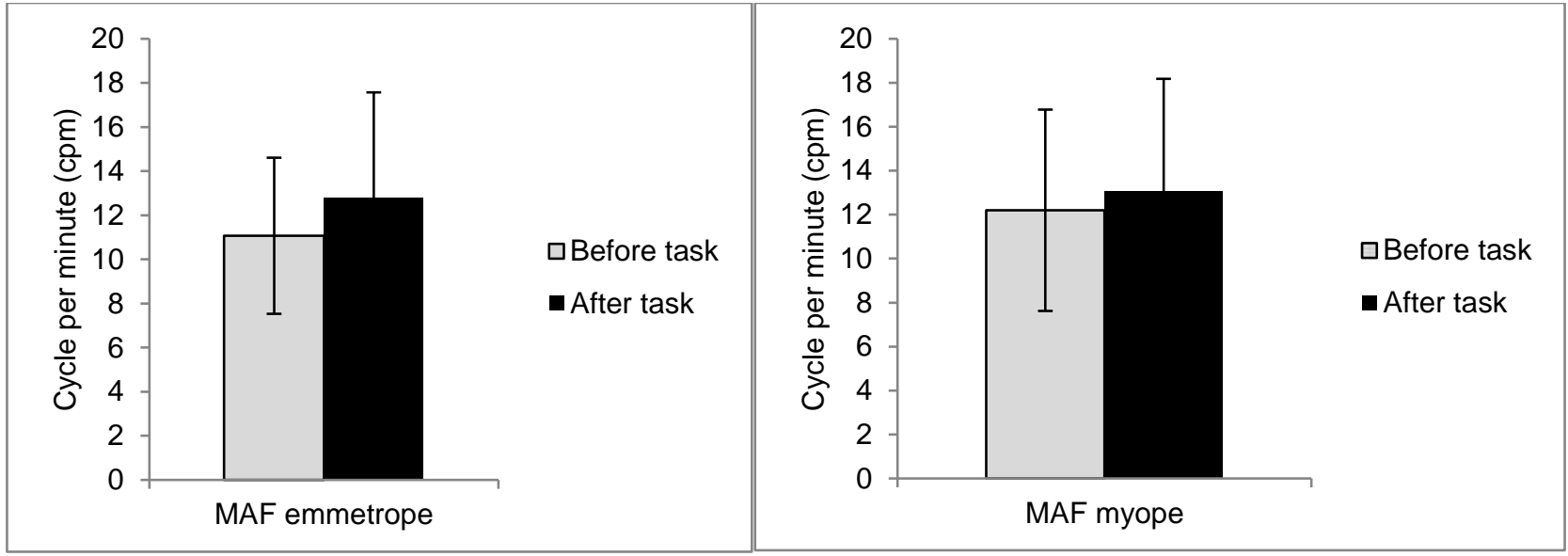

Figure 11 and 12: The insignificant effect of near task on MAF for emmetropes and myope $(p>0.05)$

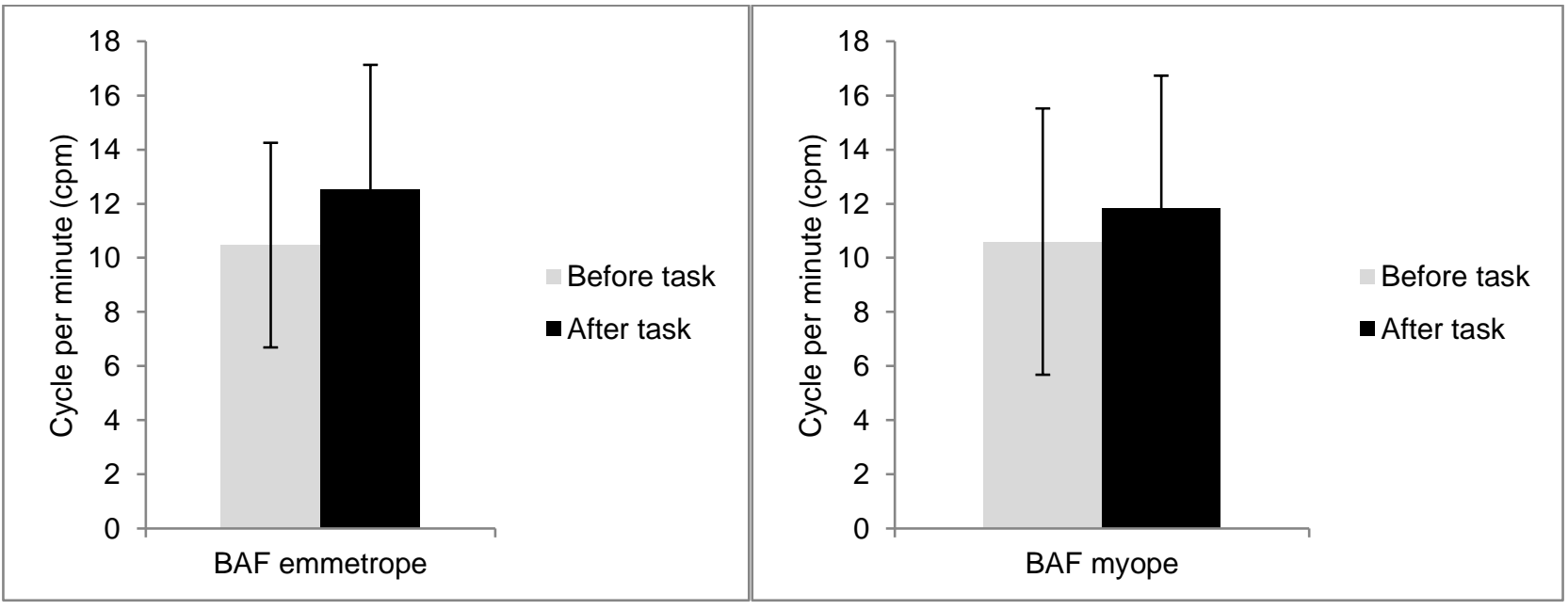

Figure 14: The insignificant effect of near task on BAF for emmetrope and myopes $(p>0.05)$

\subsection{Discussion}

After 15 minutes of exposure to near task, the result has revealed significant accommodation lag increase in young adult and children when measured through monocular estimation method (MEM) dynamic retinoscopy (Figure 3 and 4), however, neither have higher accommodation lag than the other. The result of school-aged children is very similar to adults (Gwiazda et al., 1995). Thus, the difference in tonic accommodation due to myopic shifts after near work occur whether found in children or adults were the same and showed an insignificant difference. It stated that the largest inward shifts after near work occur during the period of acquisition and progression of myopia, whether found in children or adults do not have a significant difference. Nonetheless, some age-related difference between tonic accommodation measurements and they also found the first association reported between increasing age and less myopic levels of tonic accommodation (Zadnik et al., 1999). They have stated that tonic accommodation decreased with increasing age which concluded that school-aged children would have higher accommodation response following prolonged near task rather than adults as their eyes were still in active accommodation state compared to the adults. So, based on this study, the results followed the first research rather than later, as it was found an insignificant difference between different age (young adults and children) to accommodation response following near task. This could be due to the inadequate number of subjects to rule out that conclusion.

Meanwhile, the near task has shown a significant accommodation lag increase in both myopes and emmetropes when measured through the monocular estimation method (MEM) dynamic retinoscopy (Figure 5 and 6). However, neither have higher accommodation lag than the other. Several studies showed the difference of accommodation values in myopes and emmetropes following near task such as in Zadnik et al., stated that tonic accommodation of emmetropes before the near task was significantly higher in myopes, but when they were exposed to a near task, the myopes had increasingly significant higher tonic accommodation than the emmetropes (Zadnik et al., 1999). However, there are also some studies revealed that refractive errors did not have any effect on accommodation value such as in Gwiazda \& Bauer, which stated the final tonic accommodation values after near work do not differ significantly among refractive groups (Gwiazda et al., 1995). Nevertheless, all refractive errors will undergo myopic shift when they are exposed to intense, prolonged near work as they said, the myopic shift in this study was associated with a statistically significant increase in average anterior chamber depth, vitreous chamber depth, and consequently in axial length (Hepsen et al., 2001). In conclusion, different refractive errors, be it myope, emmetrope or even hyperope, they will undergo this myopic shift due to increase of anterior chamber depth, vitreous chamber depth and the axial length when they are exposed to prolonged near work. 
Higher accommodation lag means a reduced accommodation response, needless to say, a prolonged near work was bad for the eye as it increases the accommodation lag, and it reduces the eye's accommodation response to the near task. This will then cause more accommodative effort and visual stress, that could be a precursor leading to myopia development. Accommodative effort during near work is thought to be a causative factor in the development of myopia (Hepsen et al., 2001). In another hand, accommodative facility results measured using the monocular accommodative facility (MAF) or binocular accommodative facility (BAF) have shown insignificant effects following near work in both groups of adults and children, and also in myopes and emmetropes. These results of monocular and binocular accommodative facility measurements are in agreement with previous studies, which myopes shows a significantly lower accommodative facility rate when compared with emmetropes for distance viewing conditions but not for near tasks (Radhakrishnan et al., 2007). So, in correlation to this study, near tasks did not exhibit any significant effect on the accommodation facility. The explanation for this phenomenon might be due to the long cycling times in accommodative facility was the obvious reason behind it (Radhakrishnan et al., 2007). In the near test, the vergence cue provided by the positive lenses makes it harder for the eye to relax the accommodation as the accommodation and vergence system in our eye works simultaneously. Thus, even if the accommodation relaxes, the vergence helps in making the words clear, hence there was no distinct effect of the near task to the accommodation facility.

\subsection{Conclusion \& Recommendations}

Near task has a significant effect on accommodation response using MEM retinoscopy where the lag of accommodation increases before and after task for both young adults and children together with myopes and emmetropes groups. However, the accommodation facility neither monocular accommodative facility (MAF) or binocular accommodative facility (BAF) were not affected by near work in all groups tested. As the general recommendation, the near task results focusing inaccuracy (lag of accommodation) which could increase the risk of refractive error in the future. The ergonomic approach, which interaction between the environment and behavioural modification could reduce the risk for the long term. There were wide of ergonomic guidelines available when applying for the near work every day, such as 20-20-20 rule, optimum lighting, sit position and workstation arrangement. This approach could be beneficial to the future research that links to multidiscipline approach especially when involving perception and cognition, and the risk awareness to the public.

\section{Acknowledgements}

This work was financially supported by LESTARI GRANT (Project Number: 600-IRMI/DANA KCM 5/3/LESTARI (110/2017). The authors wish to thank Optometry and Vision Science Research Centre (iROViS) and Faculty of Health Sciences, Universiti Teknologi MARA (UTTM) for the permission to conduct the study and to all participants in the study.

\section{References}

Chen, J. C., Schmid, K. L., \& Brown, B. (2003). The autonomic control of accommodation and implications for human myopia development: A review. Ophthalmic and Physiological Optics, 23(5), 401-422.

Chen, J. C., Schmid, K. L., Brown, B., Edwards, M. H., Yu, B. S. Y., \& Lew, J. K. F. (2003). AC/A ratios in myopic and emmetropic Hong Kong children and the effect of timolol. Clinical \& Experimental Optometry, 86(5), 323-330.

Ciuffreda, K. J., \& Vasudevan, B. (2008). Near work-induced transient myopia (NITM) and permanent myopia-is there a link? Ophthalmic \& Physiological Optics : The Journal of the British College of Ophthalmic Opticians (Optometrists), 28(2), 103-14.

Drexler, W., Findl, O., Schmetterer, L., Hitzenberger, C. K., \& Fercher, A. F. (1998). Eye elongation during accommodation in humans: Differences between emmetropes and myopes. Investigative Ophthalmology \& Visual Science, 39(11), 2140-2147.

Gwiazda, J., Bauer, J., Thorn, F., \& Held, R. (1995). Shifts in tonic accommodation after near work are related to refractive errors in children. Ophthalmic \& Physiological Optics : The Journal of the British College of Ophthalmic Opticians (Optometrists), 15(2), 93-97.

Gwiazda, Jane, Bauer, J., Thorn, F., \& Held, R. (1995). A dynamic relationship between myopia and blur-driven accommodation in school-aged children. Vision Research, 35(9), 1299-1304.

Gwiazda, Jane, Thorn, F., Bauer, J., \& Held, R. (1993). Myopic children show insufficient accommodative response to blur. Investigative Ophthalmology \& Visual Science, 34(3), 690-694.

Hepsen, I. F., Evereklioglu, C., \& Bayramlar, H. (2001). The effect of reading and near-work on the development of myopia in emmetropic boys: A prospective, controlled, three-year follow-up study. Vision Research, 41(19), 2511-2520.

Hsu, C.-C., Huang, N., Lin, P.-Y., Tsai, D.-C., Tsai, C.-Y., Woung, L.-C., \& Liu, C. J.-L. (2016). Prevalence and risk factors for myopia in second-grade primary school children in Taipei: A population-based study. Journal of the Chinese Medical Association.

Laughton, D. S., Sheppard, A. L., Mallen, E. A. H., Read, S. A., \& Davies, L. N. (2017). Does transient increase in axial length during accommodation attenuate with age? Clinical \& Experimental Optometry, 100(6), 676-682. PubMed. 
Liu, C., Drew, S. A., Borsting, E., Escobar, A., Stark, L., \& Chase, C. (2016). Tonic accommodation predicts closed-loop accommodation responses. Vision Research, $129,25-32$.

Mallen, E. A. H., Kashyap, P., \& Hampson, K. M. (2006). Transient Axial Length Change during the Accommodation Response in Young Adults. Investigative Ophthalmology \& Visual Science, 47(3), 1251-1254.

Morgan, I. G., Ohno-Matsui, K., \& Saw, S.-M. (2012). Myopia. The Lancet, 379(9827), 1739-1748. https://doi.org/10.1016/S0140-6736(12)60272-4

Radhakrishnan, H., Allen, P. M., \& Charman, W. N. (2007). Dynamics of accommodative facility in myopes. Investigative Ophthalmology \& Visual Science, 48(9), 43754382.

Tassinari, J. T. (2002). Monocular estimate method retinoscopy: Central tendency measures and relationship to refractive status and heterophoria. Optometry and Vision Science : Official Publication of the American Academy of Optometry, 79(11), 708-714.

Wolffsohn, J. S., Gilmartin, B., Thomas, R., \& Mallen, E. A. M. (2003). Refractive error, cognitive demand and near work-induced transient myopia. Current Eye Research, 27(6), 363-370.

Wu, L., Leung, H., Jiang, H., Zheng, H., \& Ma, L. (2016). Incorporating human movement behaviour into the analysis of spatially distributed infrastructure. PloS One, 11(1), e0147216.

Zadnik, K., Mutti, D. O., Kim, H. S., Jones, L. A., Qiu, P. H., \& Moeschberger, M. L. (1999). Tonic accommodation, age, and refractive error in children. Investigative Ophthalmology \& Visual Science, 40(6), 1050-1060. 